\title{
Using Multiple Correspondence Analysis to Measure Multidimensional Poverty in Congo
}

\author{
Samuel Ambapour \\ Bureau d'Application des Méthodes Statistiques et Informatiques, Brazzaville, Republic of Congo \\ Email: ambapour_samuel@yahoo.fr
}

How to cite this paper: Ambapour, S. (2020) Using Multiple Correspondence Analysis to Measure Multidimensional Poverty in Congo. Journal of Data Analysis and Information Processing, 8, 241-266. https://doi.org/10.4236/jdaip.2020.84014

Received: July 16, 2020

Accepted: October 9, 2020

Published: October 12, 2020

Copyright $\odot 2020$ by author(s) and Scientific Research Publishing Inc. This work is licensed under the Creative Commons Attribution International License (CC BY 4.0).

http://creativecommons.org/licenses/by/4.0/

\section{(c) (i) Open Access}

\begin{abstract}
The following analysis is based on a multidimensional understanding of poverty using a nonmonetary basic needs approach. It is ground on data from the first survey on household living conditions for poverty assessment, conducted by the National Institute of Statistics of Congo in 2005. Multiple Correspondence Analysis is applied to construct a composite indicator by aggregating several attributes likely to reflect the poverty of individuals or households. The application shows that Congolese households are not affected by the same type of poverty. Three types of non-monetary poverty are identified: infrastructure poverty, vulnerability of human existence and poverty of comfort. These households were then classified according to the composite indicator of Poverty. The results show that the incidence of poverty corresponds to the weight of poor class of about $70.67 \%$.
\end{abstract}

\section{Keywords}

Multiple Correspondence Analysis, Basic Needs, Composite Indicator of Multidimensional Poverty

\section{Introduction}

Poverty is a complex phenomenon, a multidimensional state that is cultural, economic, social and political ... Indeed, according to Alkire [1], "poverty can go hand in hand with poor health, insufficient education, low income, precarious housing, difficult work, food insecurity, loss of political responsibility". Each of these states reflects a particular aspect of individual deprivation and taken together; they illustrate the multidimensionality of this phenomenon. Thus, in recent years, in the analysis of poverty, a consensus has emerged that the monetary approach does not always capture the multiple phenomena that may impede a decent life. 
For Sen [2], measuring poverty involves two distinct operations: 1) the identification of the poor in the total population; and 2) the aggregation of statistics on the identified poor to construct a global poverty index. However, it must be noted that specifying such an index raises several conceptual and methodological questions such as: 1) which indicators of well-being should be used; 2) how can all the information concerning the poor population be summarized into a synthetic measure of poverty? The literature on the subject shows that there is diversity in the answers to these questions, and that poverty is not an objective concept. Indeed, the study of poverty in a multidimensional perspective shows the existence of several approaches.

In Congo, the National Institute of Statistics produced an income poverty profile in 2005 using data from the survey on household living conditions to assess poverty [3]. With the same data from this survey, we will measure multidimensional poverty in Congo, based on a nonmonetary basic needs approach. In concrete terms, the aim is to make a multidimensional exploration of poverty using multiple correspondence analysis from nonmonetary indicators of well-being. With this method, one possibility is to define a composite indicator of poverty by aggregating several attributes or variables likely to reflect the poverty of individuals or households; it is then on the basis of this aggregate that the various poverty measures can be made. In view of the importance that the Congo has recently been giving to the fight against poverty, the interest of this study is clear: to contribute to an in-depth knowledge of poverty in the country that can help the government authorities to make good decisions.

The rest of the text is organized as follows. Section 2 introduces the conceptual framework of poverty. Three main schools in conceptual approaches to poverty are identified. The first approach is monetary and places the conceptualization of well-being in the utility space. The second is the basic needs approach, which considers that an individual should be able to satisfy certain basic needs that are necessary to achieve a certain quality of life. The third is the capability approach, which reflects well-being through the positive rights of individuals. Section 3 describes the methodological framework by introducing some measures of multidimensional poverty that have been proposed in the literature. Section 4 is devoted to the presentation of the data, firstly by indicating the source which recalls the objectives of the survey and the collection procedures used, and secondly by specifying the non-monetary dimensions of poverty selected. In Section 5, Multiple Correspondence Analysis is applied to construct a composite indicator of poverty in Congo. Concluding remarks are provided in Section 6.

\section{Conceptual Framework}

Poverty is a complex phenomenon that requires different approaches. It has, however, become conventional to distinguish three main schools of thought on the poverty measurement: the Welfarist school, the basic needs school and the capability school. For Asselin [4] these three schools seem to agree at least on the 
following point: is judged to be poor, anyone who does not reach a reasonable minimum satisfaction of "something". What distinguishes them is the nature and level of this minimum. The following is a brief summary of these three approaches. We will therefore follow closely the presentation made by [4].

\subsection{The Welfarist School}

According to the welfarist school, "something" means economic well-being. The well-being concept is approximated to that of utility. It is defined as the degree of satisfaction achieved by an individual with the goods and services he or she consumes. In this approach, comparisons of well-being, as well as policy decisions, are based solely on the preferences of individuals. The ranking of these preferences for goods is represented by a utility function whose value is supposed to statistically summarize a person's well-being. Thus considered, utilities are the basis for social preferences including poverty comparisons.

Welfare theory is used as a reference for the analysis of income poverty. Because of the impossibility of measuring utilities, it relies on the use of income (or consumption) as a measure of well-being. In other words, if individuals share the same preferences and therefore have the same unobservable utility function and if they face the same price system, the ranking by income will be the same as the ranking by utilities through an identical pre-order relationship [5]. The Welfarist school emphasizes the importance of increasing income, through increased productivity and employment as a strategy to fight poverty.

\subsection{The Basic Needs School}

For the basic needs approach, the "something" that is lacking in the lives of the poor is a subset of goods and services specifically identified and perceived as universal, common to people of different cultures and civilizations. This poverty of "living conditions" or "poverty of existence", reflects a situation of lack in the areas of food, health, education, housing, etc. This approach to poverty is based on a humanist vision that goes beyond economics to appeal to morality and to human development in all its dimensions [6]. One of the main problems facing this approach is the determination of these basic needs, which can vary from one individual to another depending on age and gender. These basic needs consist of two elements [6] 1) the minimum necessary for a family for individual consumption; food, adequate clothing and housing, certain household items or furniture (so-called biological needs); 2) basic services that are both used and provided by the community as a whole, such as drinking water, garbage collection and sewerage, public transport, sanitation and education (access to public goods and services). This approach favours policies oriented towards the satisfaction of basic needs in the fight against poverty. Finally, it should be noted that this approach met with considerable success during the 1970s thanks to the work of the International Labour Office (ILO) during the World Conference on Employment, income distribution, social progress and the international division of la- 
bour in 1976. And, following the failures of structural adjustment programmes in developing countries in the 1980s, it helped to give a social orientation to the World Bank's development policies.

\subsection{The Capability School}

For this school, the "thing" that is lacking refers neither to utility nor to the satisfaction of basic needs, but to human abilities, or capacities. This approach, which stems from the work of Sen [7] [8], winner of the 1998 Nobel Prize in Economics (Nobel Prize for the Poor according to the British press), differs from the basic needs approach and is part of a reflection on social justice, equality and inequality. The three main components of this approach are "commodities", "functionings" and "capabilities". Commodities correspond to all goods and services and have the characteristic of making "functionings" possible. The functionings take into account the achievements of individuals, i.e. what they "are" and what they "do" with their resources. Capabilities are the set of opportunities that a person can choose from: they are the various combinations of functionings that a person can perform. Thus, the capability school makes it possible to approach poverty by considering it as the result of an inability to seize the opportunities that arise due to a lack of capacity resulting from poor health, insufficient education, nutritional imbalances, etc. Poverty reduction strategies would focus here on human capacity building.

It should be specified that the capability approach has had considerable success internationally. In 1990, the UNDP drew inspiration from this approach in order to lay the foundations for the now widely used concept of "human development" and the indicator derived from it, known as the Human Development Index (HDI). The World Bank too has not remained indifferent to this approach; indeed, it has moved from a policy of liberal orthodoxy to a strategy that includes good governance and the fight against poverty and inequality. Since 1997, in association with the IMF, it has placed the fight against poverty at the centre of social policies.

\section{Methodological Framework}

This section provides a brief review of the literature on key measures of multidimensional poverty. Two families of methods are distinguished in the measurement of multidimensional poverty, namely, axiomatic and nonaxiomatic methods. Axiomatic methods are rather an extension to two or more dimensions of certain classes of poverty indices proposed in the unidimensional framework. In nonaxiomatic methods, a distinction is made between methods based on aggregated data and methods concerning individual data. In what follows, we draw heavily on the general statements made earlier [9] [10] [11] [12].

\subsection{Axiomatic Methods}

Let us then consider a population where each individual or household 
$i(i=1,2, \cdots, n)$ has a vector $x_{i}=\left(x_{i 1}, x_{i 2}, \cdots, x_{i m}\right) \quad$ of $m$ attributes $j=(1,2, \cdots, m)$; with $x_{i} \in R_{+}^{m}$ where $R_{+}^{m}$ is the non-negative orthant of the Euclidean space $R^{m}$; let $X$ the matrix $n \times m$, where each element $x_{i j}$ gives the quantity of attributes $m$ that the individual $i$ has. Let now $z_{j} \in Z$ the poverty line for each attribute $m$, with $Z \in R_{++}^{m}$ the positive orthant of the Euclidean space $R^{m}$. We can then consider the general form of a class of multidimensional poverty measures by the following equation:

$$
P(X, z)=F\left(\pi\left(x_{i}, z\right)\right)
$$

where $\pi($.$) is the individual poverty function, indicating how the different$ dimensions of poverty are to be aggregated at the individual level. In contrast, the function $F($.$) indicates how individual poverty should be aggregated to$ arrive at an overall poverty measure. Note, for example, that if the function $F($.$) is additive we have:$

$$
P(X, z)=\frac{1}{n} \sum_{i=1}^{n} \pi\left(x_{i}, z\right)
$$

And if the function $\pi($.$) is an indicatrix function which$

$$
\pi\left(x_{i}, z\right)=\left\{\begin{array}{ll}
0 & \text { if } x_{i j} \geq z_{j} \\
1 & \text { otherwise }
\end{array} \quad \forall j=1,2, \cdots, m\right.
$$

Then we get a multidimensional extension of the poverty index. The properties of $\pi($.$) and F($.$) depend on axioms that the measure P(X, z)$ must not violate and which, for the most part, constitute a multidimensional extension of a set of desirable properties for monetary indexes. Several multidimensional poverty indexes have been proposed in the literature. Some are even obtained from different combinations of a number of axioms. For example, three forms of $\pi($.$) which have been proposed in the literature can be presented as$ an indication.

$$
\begin{gathered}
\pi\left(x_{i}, z\right)=\sum_{j=1}^{m} \alpha_{j}\left(1-\frac{x_{i j}}{z_{j}}\right)^{\alpha} \\
\pi\left(x_{i}, z\right)=\sum_{j=1}^{m} \alpha_{j}\left(1-\left(\frac{x_{i j}}{z_{j}}\right)^{\alpha}\right) \\
\pi\left(x_{i}, z\right)=\sum_{j=1}^{m} \alpha_{j} \log \left(\frac{z_{j}}{\min \left(x_{i j}, z_{j}\right)}\right)^{\alpha}
\end{gathered}
$$

\subsection{Nonaxiomatic Methods}

Aggregated indicators provided either by the World Bank such as the Quality of Life, Human Development Index (QLHDI) or by the UNDP such as the Human Development Index (HDI) or the Human Poverty Indicators (HPI) will not be discussed here. We will therefore limit ourselves to methods based on individual data. However, the framework that we have been given obliges us to confine 
ourselves to a narrow field of measurements by concentrating on measurements using: fuzzy set theory, information theory, distance function and statistical methods, one of which, multiple correspondence analysis, will be used in the following.

\subsubsection{Fuzzy Set Theory Approach}

If $N$ is the whole population of $n$ individuals and $\mathrm{P}$ is the subset of the poor in that population, then from the above it can still be written that:

$$
\left\{\begin{array}{l}
x_{i j}<z_{j} \Leftrightarrow i \in \mathrm{P} ; \pi_{j}\left(x_{i j}\right)=1 \\
x_{i j} \geq z_{j} \Leftrightarrow i \notin \mathrm{P} ; \pi_{j}\left(x_{i j}\right)=0
\end{array}\right.
$$

This boolean logic does not seem to us very suitable for the study of poverty as a vague concept with ill-defined boundaries. We shall therefore see how to soften this abrupt division of the population into two classes and subsequently admit that the transition from a state of deprivation to a situation of nonprivation is gradual. To do this, we adopt the new concept of gradual belonging of an element of a whole introduced by Zadeh [13] and developed by Dubois and Prade [14]. In this so-called fuzzy logic, we consider a more general function of belonging, varying uniformly between zero and one. Three cases are observed:

$$
\left\{\begin{array}{l}
\pi_{j}\left(x_{i j}\right)=0 \\
0<\pi_{j}\left(x_{i j}\right)<1 \\
\pi_{j}\left(x_{i j}\right)=1
\end{array}\right.
$$

In this fuzzy logic applied to poverty, we will say that: $\pi_{j}\left(x_{i j}\right)=0$ if the individual $i$ is not poor in a sure way; $0<\pi_{j}\left(x_{i j}\right)<1$ if the individual $i$ is partially poor; $\pi_{j}\left(x_{i j}\right)=1$ if the individual $i$ is totally poor. The problem here, then, is to choose from among the possible membership functions, the one most appropriate for each of the indicators of deprivation. The most widely used are those of Cerioli and Zani [15] called the totally fuzzy approach and that of Cheli and Lemmi [16] named the totally fuzzy and relative approach. The resulting poverty index can be defined as the arithmetic mean of the membership functions of individuals or households:

$$
P=\frac{1}{n} \sum_{i=1}^{n} \pi\left(x_{i}\right)
$$

This method was applied by the author to measure multidimensional poverty in Congo with the same data used in this article [17].

\subsubsection{Information Theory Approach}

It is also sometimes called the entropy approach. This information theory was originally developed by engineers. Its adaptation to measures of inequality and poverty was made by E. Maasouami [18]. The basic principles of this approach can be explained in a simplified way by following D. Miceli [19]. Reconsider the previous notations where each individual or household $i(i=1,2, \cdots, n)$ has a 
vector $x_{i}=\left(x_{i 1}, x_{i 2}, \cdots, x_{i m}\right)$ of $m$ attributes $j=(1,2, \cdots, m)$; we note by $x_{i j}$ the value of the attribute $j$ corresponding to the individual or household $i$. The different elements $x_{i j}$ can then be arranged in a well-being matrix $\underset{n, m}{X}=\left[x_{i j}\right]$ where one can read in the $i$-th row the well-being situation faced by the individual or household $i$ according to the $m$ indicators, and in the $j$-th column, the distribution of the $j$-th indicator for the individuals.

The proposal made [18] is to replace the $m$ information on all indicators of well-being with a single composite indicator $x_{c}$ synthesizing all the aspects of well-being selected and represented by a vector with $n$ components, one for each individual. In fact, it suggests that for each individual or household $i$ to replace the vector $\left(x_{i 1}, x_{i 2}, \cdots, x_{i m}\right)$ by the scalar $x_{c i}$ and thus find a function that aggregates or summarizes the information provided by the $m$ indicators selected at the outset.

The question is then that of the choice of the aggregation function used to construct the composite indicator of well-being $x_{c i}$. The proposed solution [18] is to find a vector $x_{c}$ whose distribution is as close as possible to those of all the indicators of well-being by using criteria of divergence between distributions borrowed from information theory. In this case, the proximity criterion is to minimize the following generalized entropy function:

$$
D_{\gamma}\left(x_{c}, X ; \alpha\right)=\frac{1}{\gamma(\gamma+1)} \sum_{j=1}^{m} \alpha_{j}\left[\sum_{i=1}^{n} x_{c i}\left[\left(\frac{x_{c i}}{x_{i j}}\right)^{\gamma}-1\right]\right]
$$

with $\gamma \neq 0,-1$, and where $\alpha_{j}$ represents the weight to be assigned to the indicator $j$. The solution for the general case $(\gamma \neq 0,-1)$ of this minimization is presented by:

$$
x_{c i} \infty\left[\sum_{j=1}^{m} \delta_{j}\left(x_{i j}\right)^{\gamma}\right]^{-\frac{1}{\gamma}}
$$

with $\delta_{j}=\frac{\alpha_{j}}{\sum_{j=1}^{m} \alpha_{j}}$.

In his study [19] on multidimensional poverty in Switzerland, Miceli proposed the following form for the composite indicator of well-being:

$$
x_{c i}=\sum_{j=1}^{m} \delta_{j} s_{i j}
$$

where $\delta_{j}$ is the weight of the well-being indicator $j$ and $s_{i j}$ the value taken by the indicator $j$

with $s_{i j}=\frac{x_{i j}}{\sum_{i=1}^{n} x_{i j}}$.

A roughly similar application of information theory was used to analyze the 1995 Israeli census data [9]. This theory was also adopted not long ago to con- 
struct multidimensional poverty indexes with data from the 2000 Indonesian Family Life Survey [20].

\subsubsection{Distance Function Approach}

The distance function is a concept used in production theory and particularly in efficiency analysis [21]. Lovell et al. [22] were probably the first to adopt this concept in the context of the analysis of household behaviour. Subsequent research followed: multidimensional poverty [9], well-being [23], human development dimensions [24] and human development index [25]. The distance function can be defined as an approach that seeks to measure how much to adjust the set of attributes of an individual to achieve the reference level of well-being [25]. This is done by using a measure of the distance between a vector of goods (resources and capabilities) of that individual and a reference vector. The analytical expression of the distance function is as follows:

$$
\left(x_{i}, W\right) \equiv \min _{d}\left\{d: W\left(d x_{i}=W^{*}, d>0\right)\right\}
$$

where $x_{i}$ is a vector of characteristics of the individual's condition $i, W$ the weight function (welfare) chosen, $W^{*}$ the weight function of the reference level and $d$ represents the measure of the distance that should correspond to the amount of the minimum adjustment to be made to bring the individual's condition back to the reference level. In most of the applications cited above for the analysis of this problem, a translog function that aggregates all of the welfare characteristics of each agent and normalizes to one of them is used as a measure of welfare. In their approach called the lower convex hull approach, Anderson, Crawford and Leicester [25] have proposed a more general formulation that does not specifically require the choice of an aggregation function. It relies on some general properties (monotonicity and quasi-concavity) of the function $W$ to derive the lower bound of the distance measure of relative well-being as follows:

$D\left(x_{i}\right) \equiv \min _{d} d\left\{d: W\left(d x_{i}\right)=W^{*}, d>0, \forall W\right.$ monotone and quasi-concave $\}(14)$

Taking into account the properties of $W$, the sets of well-being levels are then convex with respect to the origin. Let $X$ be a finite dataset, it is possible to derive a convex set whose lower bound which is convex curve $\inf (X)$ corresponds to the level of well-being of the reference individual. This curve has a particularly useful interpretation in the case of analyzing poverty states: "it is what we will term the Rawlsian Frontier, the set of potentially poorest agents in the sample, and consequently represents the frontier of poorest individuals in the population" [25].

\subsubsection{Statistical Methods}

As before, let us now note by $x_{i}$ the indicator of wealth for the household or the individual $i, x_{i j}$ its endowment in basic needs $j$ and by $\alpha_{j}$ the weight of each basic need, the analytical expression of $x_{i}$ is defined by:

$$
x_{i}=\alpha_{1} x_{i 1}+\cdots+\alpha_{m} x_{i m}
$$

Two groups of statistical methods of multivariate analysis allow us to study this 
relationship [12]: descriptive methods and latent variable models.

\section{1) Descriptive methods}

Here we adopt the inertia approach to present these methods. To do so, let us reconsider the matrix $\underset{n, m}{X}$. Each of the $n$ rows of matrix can be treated either as a vector or a point in $R^{n, m}$ called the individuals' space. The entire matrix constitutes a set of $n$ points in $R^{m}$. The principle of this approach is the following: find in $R^{m}$ a sub-space of dimension $I(l<m)$ that is the best for the set of points in the least square sense. The result is well known: it is the $I$ dimensional subspace generated by the $I$ first eigenvectors of symmetric matrix $X^{\prime} X$ corresponding to the $I$ first eigenvalues. Thus, the inertia approach has situated lines on the Euclidean space where the set of points is located; this system of lines which are mutually perpendicular is taken as a system of coordinate axes and the coordinates are called factors. In the poverty analysis the first factor, (the principal axis of inertia or line in the direction of which the inertia of the set of points attains its maximum) is an interesting candidate for the composite indicator of poverty. Depending on the nature of the data in the table $X$ two methods are often used: 1) principal component analysis [26] in the case of quantitative variables; the Euclidean metric is then required to measure the proximity between observations; 2) multiple correspondence analysis [26] [27] which is an extension of correspondence analysis [28], in the case of categorical variables and using a particular one, the $\chi^{2}$ metric.

A third method, namely 3) cluster analysis [26] [29] is often used. Let us note by $Q$ a partition of all individuals $I$ (all households) into $q$ clusters (here $q=2$; poor and non-poor); $Q$ is a finite set of non-empty $q$ parts of $I$ two to two of empty intersection and whose combine is $I$. This is written:

$$
\forall q \in Q, q \subset I ; \forall q, q^{\prime} \in Q ; q \cap q^{\prime}=\varnothing \Leftrightarrow q \neq q^{\prime} ; I=\cup(q \mid q \in Q)
$$

Let us note by $g_{q}$ the center of gravity of the cluster $q$. And one supposes that the $g_{q}$ are provided with mass $n_{q}$ and each point $x_{i}$ with mass $n_{i}$. The inertia of the cluster $q$ in relation to its center of gravity is:

$$
I_{n}(q)=\sum_{q} \sum_{x_{i} \in q} n_{i} d^{2}\left(x_{i}, g_{q}\right)
$$

this quantity is called within cluster inertia ( $d^{2}$ distance squared). We can also define the inertia of $g_{q}$ in relation to the center of gravity $g$ of the set of points:

$$
I_{n}\left(g_{q}\right)=\sum_{q} n_{q} d^{2}\left(g_{q}, g\right)
$$

This quantity is called between cluster inertia. Then, Huyghen's equation provides a decomposition of total inertia $I_{n}(t)$ into within cluster and between cluster inertia:

$$
I_{n}(t)=I_{n}(q)+I_{n}\left(g_{q}\right)
$$

The global quantity of a partition is related to the homogeneity within the clusters. $I_{n}(t)$ being a constant quantity, it is thus a question of minimizing the quantity relative to the within cluster, or to maximize the quantity relative to the 
between cluster inertia. Cluster analysis is often used in relationship with the two previous methods. In this case, the objects to classify are located by their coordinates on the first axes of the analysis.

As far as applications are concerned, an interesting illustration of principal component analysis has been made by Klasen [30]. Recently, a lot of data have been collected in developing countries, particularly in Africa, as part of poverty reduction strategies. And, multiple correspondence analysis has often been used to study these data [31]. Ferro-Luzzi et al. [32] have thus combined factor and cluster analysis to identify the subpopulation of poor in Switzerland.

\section{2) Latent variable models}

A more elegant mathematical presentation of the three methods described here can be found in Krishnakumar's paper [33].

\section{a) Factor Analysis}

Here, the observed values are postuled to be linear functions of a certain number of unobserved latent variables called factors:

$$
y=\Lambda f+\varepsilon
$$

where $y$ represents the observed variables, $f$ the latent variables and $\Lambda$ the coefficient matrix. In the study cited above [32], this method was used in conjunction with cluster analysis

\section{b) The MIMIC Model (Multiple Indicators, Multiple Causes)}

According to this model, the observed variables result from the latent factors and the latent factors themselves are caused by other exogenous variables denoted here as $x$.

$$
\left\{\begin{array}{l}
y=\Lambda f+\varepsilon \\
f=\beta^{\prime} x+\varsigma
\end{array}\right.
$$

As in Factor Analysis, $y$ refers to indicators, $f$ to latent variables while here $x$ refers to "causes". For the application of this model to the study of poverty, see the text by Naga and Bolzani [34].

c) Structural Equations Model

This model can be summarized as follows by including the following different equations:

$$
\left\{\begin{array}{l}
A y^{*}+B x^{*}+u=0 \\
y=\Delta y^{*}+\varepsilon \\
x=\Phi x^{*}+\xi
\end{array}\right.
$$

where $y^{*}$ refers to latent endogenous variables, $x^{*}$ refers to latent exogenous variables, $y$ and $x$ are the observed indicators corresponding to $y^{*}$ and $x^{*}$. In the reference already quoted above [33], an application of this model is illustrated.

\section{The Data}

\subsection{Data Source}

The process of drafting the Poverty Reduction Strategy Paper in Congo required a 
survey of household living conditions, known as the Congolese Household Survey for Poverty Assessment. This survey was carried out by the National Institute of Statistics of Congo, with technical support from the World Bank, the Economic and Statistical Observatory of Sub-Saharan Africa (AFRISTAT), thanks to financial support from the Congolese Government, the World Bank (BD) and the United Nations Development Programme (UNDP). The general objective of the survey was to provide current, reliable and relevant data on household living conditions with a view to finalizing the Poverty Reduction Strategy Paper (PRSP) and monitoring the achievement of the Millennium Development Goals (MDGs). The specific objectives were as follows: 1) to construct an income poverty line to be used for future comparisons; 2) to produce an income poverty profile; 3) to produce a number of indicators selected from the Poverty Reduction Strategy Paper; 4) to carry out certain sector studies with a view to finalizing the Poverty Reduction Strategy Paper; 5) provide basic statistics to assist in the preparation of national accounts (household consumption at the final level for the achievement of resource-use balances, etc.); 6) provide weights for the calculation of a new household final consumer price index within the framework of the price harmonization project of the Communities of Central African States. The survey consisted of two main modules and a secondary component: 1) a module on household consumption, which made it possible to analyse income poverty, carry out other in-depth studies and provide some basic statistics; 2) a module on basic indicators of well-being, a tool developed by the World Bank, the United Nations Development Programme (UNDP), the United Nations Children's Fund (UNICEF) and the International Labour Organization (ILO) to provide the country with a means of producing essential statistical indicators very rapidly; 3 ) a specific component on price collection. In the absence of a national consumer index, it was necessary to have a tool to be used as a deflator of consumer expenditure, in order to take account of price differences between the various departments of the country.

This survey is the first of its kind, carried out in Congo with national coverage. It was designed to serve as a baseline survey in the context of knowledge of poverty in the Congo. Of the 5256 households drawn, only 5146 could be surveyed totally or partially, i.e. a coverage rate of $97.9 \%$. After data auditing, and in order to preserve harmony in the two main components of the survey, 5002 households were fully covered, for a completion rate of 95.2 per cent.

\subsection{Non-Monetary Dimensions of Poverty: Some Comments}

This is based on the second module of the survey concerning the basic indicators of well-being used to construct the composite indicator of non-monetary poverty. It is therefore the basic needs approach that is adopted here, the themes of which are the subject of a brief commentary.

\subsubsection{Education}

The influence that men's education can have on their productivity and economic 
growth had been emphasized by classical economists, notably Adam Smith. Today, the role of education is glorified by international institutions. Indeed, it is the second point of the Millennium Development Goals (MDGs). Education is therefore one of the most important dimensions of poverty analysis. It can, however, be captured by several indicators, each characterizing a particular aspect of the mobilization of this asset. For the purposes of this poverty study, the variables used to characterize education are: literacy, time to access a primary school and time to access a secondary school. It should be noted that the literacy rate is $80.4 \%$ in Congo. This is still a good performance, as the rate is generally below $50 \%$ for African countries south of the Sahara.

\subsubsection{Health}

Health is now seen as a component of human capital, along with education and nutrition. It is an essential element of well-being (only men have wealth). A healthy individual is economically more productive and thus contributes to economic growth. Investing in health should be a commitment by a state to reduce or alleviate poverty. This is one of the purposes pursued by the Poverty Reduction Strategy Paper and the National Health Development Plan of Congo. Health is the fourth, fifth and sixth point of the Millennium Development Goals. Information constraints mean that health is captured here by only two indicators: the time taken to access health infrastructures and morbidity. For the latter indicator, its rate in the Congo is estimated at 39\% in 2005.

\subsubsection{Nutrition}

Eradicating extreme poverty and hunger is the first point of the Millennium Development Goals. The Economic Commission for Africa noted in 2005 that since the launch of these goals in Africa, the proportion of people without enough food has fallen by only 3 points. Hunger still prevails. This is particularly true in rural Africa. There are many indicators that capture this important dimension of poverty. Unfortunately in the case of this survey, the indicator selected only covers food problems.

\subsubsection{Drinking Water}

Water is considered to be man's first food. It fulfills two essential functions: physiological and biological. To deprive oneself of water is therefore to deprive oneself of life. It is a source of development and progress and has many applications. Access to water, its availability and quality is therefore a major challenge. In the case of our study, in order to assess this dimension, we refer to the partial indicators that are the water supply sources and the time taken to have access to a drinking water point. In Congo, $68.5 \%$ of households have access to a drinking water source.

\subsubsection{Electricity}

The role that electricity plays or has played in economic growth is well established. The use of electricity therefore contributes to the improvement of living conditions and quality of work. It is therefore a source of development, progress, 
well-being, comfort and leisure, and its applications are constantly increasing. The partial indicators used to assess the electricity dimension of non-monetary poverty are: lighting sources, means of lighting and fuel types. According to the results of the survey, it emerges that the majority of the population uses kerosene lamps ( $70.1 \%$ of households) for lighting, compared to $27 \%$ of households subscribing to the National Electricity Company. For cooking purposes, $55.1 \%$ of households use firewood, against 1.3\% using electricity.

\subsubsection{Housing}

Housing is an important dimension of poverty. Indeed, it is a crucial problem especially in urban areas for the economically weak, given the high cost of land and materials. In this case, it is difficult to have access to quality housing. And in this context, it is the poorest who find themselves in precarious housing, in areas where there is generally no infrastructure and services. Housing thus becomes a factor of exclusion and can be considered as an indicator of poverty. The indicators defined to measure the housing dimension of non-monetary poverty in this study are: the nature of roofs, walls, soil and the occupancy status of the dwelling. Concerning the material used for the roof, the survey revealed that $83.3 \%$ are covered with sheet metal and $15.7 \%$ with straw. As for the material of the walls, one house out of two has walls made of materials considered durable: cement blocks (39.3\%) or clay bricks (11.9\%). Overall, 55.5\% of Congo's dwellings have a cement floor, compared to $41 \%$ with clay bricks.

\subsubsection{Sanitation}

Sanitation is closely linked to housing. It is, in a way, the infrastructure part of the latter (roads, sewage disposal system ...). A certain quality of life and the assurance of health security are conditioned by a healthy and pleasant living environment. The partial indicators selected are the type of toilets, the way in which household waste and waste water is disposed of. In Congo, more than half of the dwellings (51.8\%) have a sanitation system deemed to be healthy. With regard to household waste treatment, the survey results show the predominance of the use of incineration, which consists of burning waste.

\subsubsection{Communication}

As an essential right, as a "fundamental freedom", communication (better known as the right to information) is part of the first generation of human rights. In the context of poverty reduction, the communication dimension can be seen in terms of people's access to the media. Indeed, a man who is well informed about the problems of society is better able to contribute to the development of his country than one who is under-informed. The communication dimension is captured by indicators such as household ownership of a television, radio or telephone. It should be noted that among these indicators, only the radio is owned by more than half of Congolese households (56.5\%). Television sets and telephones are more common in urban households, $38 \%$ and $48.9 \%$ respectively, compared to $3.9 \%$ and $9.8 \%$ in rural households. 


\subsubsection{Goods of Comfort, Equipment and Other Assets}

While poverty is characterized first and foremost by a lack of the necessities of life, it is also characterized by a lack of material comfort. The results of the survey show that, with regard to household appliances, $8.1 \%$ of households own a refrigerator, $16.8 \%$ an iron and $8.9 \%$ a sewing machine. They also indicate that, for furniture equipment, $94.5 \%$ of households have a bed or mattress and $17.3 \%$ have a modern armchair. As for means of transport, 1.9\% of households have a car, $1.7 \%$ a motorcycle, $6.2 \%$ a bicycle and $4.1 \%$ a pirogue. With regard to assets, the survey shows that $27 \%$ of Congolese households own land.

\section{Multiple Correspondence Analysis of Nonmonetary Poverty Dimensions}

The statistical approach based on the inertia criterion is used to study multidimensional poverty in Congo. In order to do so, the Multiple Correspondence Analysis (MCA) is then adopted for all the analyses that will follow. We first show how this technique can be applied to aggregate the non-monetary dimensions of poverty selected to construct the composite poverty indicator. The two main steps in the construction of this indicator are then indicated, followed by the preliminary and final MCA of the non-monetary dimensions of poverty corresponding to these two steps. The scores of different indicators of the final MCA are then analysed. We conclude by the determination of the incidence of multidimensional poverty in Congo.

\subsection{Functional Form of the Composite Indicator of Poverty (CIP)}

Asselin [35] is without a doubt the first to have used MCA to construct a composite poverty indicator. According to this author, let us adopt the following notations: $K$ the total number of primary indicators; $I_{k}$ a primary indicator with $J_{k}$ categories; and by $J=\sum_{k=1}^{K} J_{k}$ the total number of categories.

Subsequently the $J_{k}$ are binary variables $0 / 1$ taking the value 1 when the population unit has the category $J_{k}$. The statistical problem to be solved is: how to aggregate these primary indicators into a single simple composite indicator that has the property of being a good summary of the information provided by the initial indicators? The first step is then to perform MCA of the indicatrix matrix $X(N, J)$ of $N$ observations and $K$ primary indicators decomposed into $J_{k}$ binary variables. This is done by applying the correspondence analysis program to the indicatrix matrix $X$. This computer program provides, as we know, a series of functions or factors defined on the set of observations noted by $F_{i}$. Each factor corresponds to a positive real number, between 0 and 1 , called the eigenvalue, which is noted by $\lambda: \lambda_{1}$ for the first factor (value of inertia on the first axis), $\lambda_{2}$ for the second (value of inertia on the second axis), etc. In fact $\lambda_{i}$ measures the absolute importance of the $i$-th factor and we have $\lambda_{1}>\lambda_{2}>\lambda_{3}>\cdots$. The ratio $\tau_{i}$, from $\lambda_{i}$ to the sum of the eigenvalues, measures the relative importance of the $i$-th factor. It is called the percentage of inertia extracted by the $i$-th factor. 
In a second step, the results obtained by the multiple correspondence analysis are used to construct the composite indicator. From all of the above, Asselin proposed the functional form of the composite poverty indicator that follows:

$$
C_{i}=\frac{\sum_{k=1}^{K} \sum_{j_{k=1}}^{J_{k}} W_{j_{k}}^{k} I_{j_{k}}^{k}}{K}
$$

where $W_{j_{k}}^{k}$ is the category-weight (standardized score on the first axis, $\frac{\text { score }}{\sqrt{\lambda_{i}}}$ ) of category $J_{k} ; \lambda_{i}$ being the first eigenvalue from multiple correspondence analysis. With regard to formula (22), it can be seen that the composite poverty indicator is the simple average across dimensions (variables) of the weighted sum of each binary modality of each dimension.

\subsection{Steps in the Construction of the Composite Indicator of Poverty}

The construction of a composite multidimensional poverty indicator through multiple correspondence analysis is a two-step approach: 1) a first MCA is carried out on a set of available and relevant variables characterizing household living conditions. The first factorial axis of this MCA highlights the phenomenon of poverty and certain variables used in the analysis of the composite indicator; 2) a second MCA is then carried out with the aim of reducing the number of variables resulting from the first analysis. This reduction is done according to a certain number of criteria, the main one being the first axis ordering consistency (FAOC), which consists in selecting the relevant variables to be used in the construction of the Composite Indicator of Poverty (CIP). This property consists, for a given primary indicator, of ensuring that the latter's ordinal welfare structure is respected by the ordinal structure of the coordinates (scores) of its modalities on the first factorial axis. This criterion is a necessary condition for the CIP to effect an ordering of households in accordance with their level of welfare.

Other secondary criteria exist, such as measures of discrimination or sprawl on the first axis. Some automatic procedures implemented in some software such as the homogeneity analysis procedure in SPSS allow this selection to be carried out. In principle, this second multiple correspondence analysis should improve the explanatory power of the first factorial axis.

\subsection{Preliminary MCA}

Preliminary MCA was performed with 5002 rows (households) and 81 columns (modalities). The list of 38 variables is presented in Table 1 . The results of MCA are presented in Figure 1 that represent the configuration of points in projection plane formed by the first two axes. The first two eigenvalues are $\lambda_{1}=0.2174$ and $\lambda_{2}=0.0878 ; \tau_{1}=18.72$; and $\tau_{2}=7.56$. The plane $F(1,2)$ cumulates nearly $1 / 3$ of the total inertia $(26.27 \%)$ including $18.72 \%$ on the first axis. The plane $F(1,2)$ shows the indicators of well-being spread out on a parabolic crescent (Figure 1): this is the "Guttman effect", an indication of a strong gradient in 
the data. In other words, the data are arranged in a series that is not only on axis 1, but in the plane. This indicates that the factor 2 is a second-degree function of the factor 1:

$$
F_{2}=a\left(F_{1}\right)^{2}+b F_{1}+\gamma
$$

In the study of poverty, it is often classic to see on the first axis an opposition between rich and poor and to qualify this axis as "poverty-rich". This is indeed the case here. However, our analysis in the plane $F(1,2)$ will be done by following our parabolic curve and this clockwise from the quadrant $(-,-)$, to the quadrant $(+,-)$. Poverty is defined in the plane $F(1,2)$ by two quadrants: the quadrant $(-,-)$ and the quadrant $(-,+)$.

In the first quadrant $(-,-)$, that is $F_{1}<0 ; F_{2}<0$, Poverty is mainly described in terms of accessibility to basic social services: health, education (primary and secondary), food market and transport. Indeed, the minimum time needed for each household to reach the nearest social service on foot is more than 30 minutes (considered as the poverty line). They only have access to an unsafe water source. In this framework, poverty is also described in terms of household living conditions, specifically those characterizing housing construction materials and sanitation. It can be seen that these poor illiterate or partially illiterate households have houses with straw roofs, walls and floors made of mud and the drainage of water and garbage is done in nature. They use wood for cooking. Although these households are poor, it should be noted that they own some assets: dugout canoe, bicycle, livestock, poultry and land.

In the quadrant $(+,-)$, i.e. $F_{1}<0 ; F_{2}>0$, poverty is still found in its dimension of living conditions. These poor households, which have no access to electricity, live in houses without any comfort: no mattress, no modern chair, no refrigerator, no iron. The means of communication are also absent: no television, no radio, no telephone. As for sanitation, garbage is either buried or burned. Even worse, these households have food problems.

Table 1. Preliminary list of 38 variables for the Composite Indicator of Poverty.

\begin{tabular}{cc}
\hline Variables & Variables \\
\hline Education & Energy \\
Literacy rate & Type of lighting \\
Access to a primary school in less than 30 minutes & Electricity \\
Access to a secondary school in less than 30 minutes & Fuel \\
Health & Communication \\
Access to health services in less than 30 minutes & Television \\
Consultation of health services & Radio \\
Drinking water & Telephone \\
Source of drinking water & Access to public transport \\
Access to water in less than 30 minutes & Goods of comfort, equipment, \\
Nutrition & and other assets \\
\hline
\end{tabular}




\section{Continued}

$\begin{array}{cc}\text { Food problems } & \text { Iron } \\ \text { Access to the food market in less than } 30 \text { minutes } & \text { Refrigerator } \\ \text { Housing } & \text { Micro-computer } \\ \text { Nature of the roof } & \text { Sewing machine } \\ \text { Nature of walls } & \text { Mattress/bed } \\ \text { Nature of floor } & \text { Modern armchair } \\ \text { Housing occupancy status } & \text { Bycicle } \\ \text { Sanitation } & \text { Motorcycle } \\ \text { Type of toilets } & \text { Car or truck } \\ \text { Disposal of household waste } & \text { Canoe } \\ \text { Sewage disposal } & \text { Cattle } \\ & \text { Cheep, goats and other animals } \\ & \text { Poultry } \\ \end{array}$

The quadrant $(+,+)$, that is $F_{1}>0 ; F_{2}>0$, characterizes an intermediate situation between poor and non-poor. Indeed, these literate households living in houses with solid roofs, solid walls, cement or tiled floors are either housed free of charge or are renters. Access to basic social services (schools, hospitals, food market, transportation) is within 30 minutes. The same is true for access to water, including a clean water source. However, these households do not own land or poultry. They use charcoal for cooking.

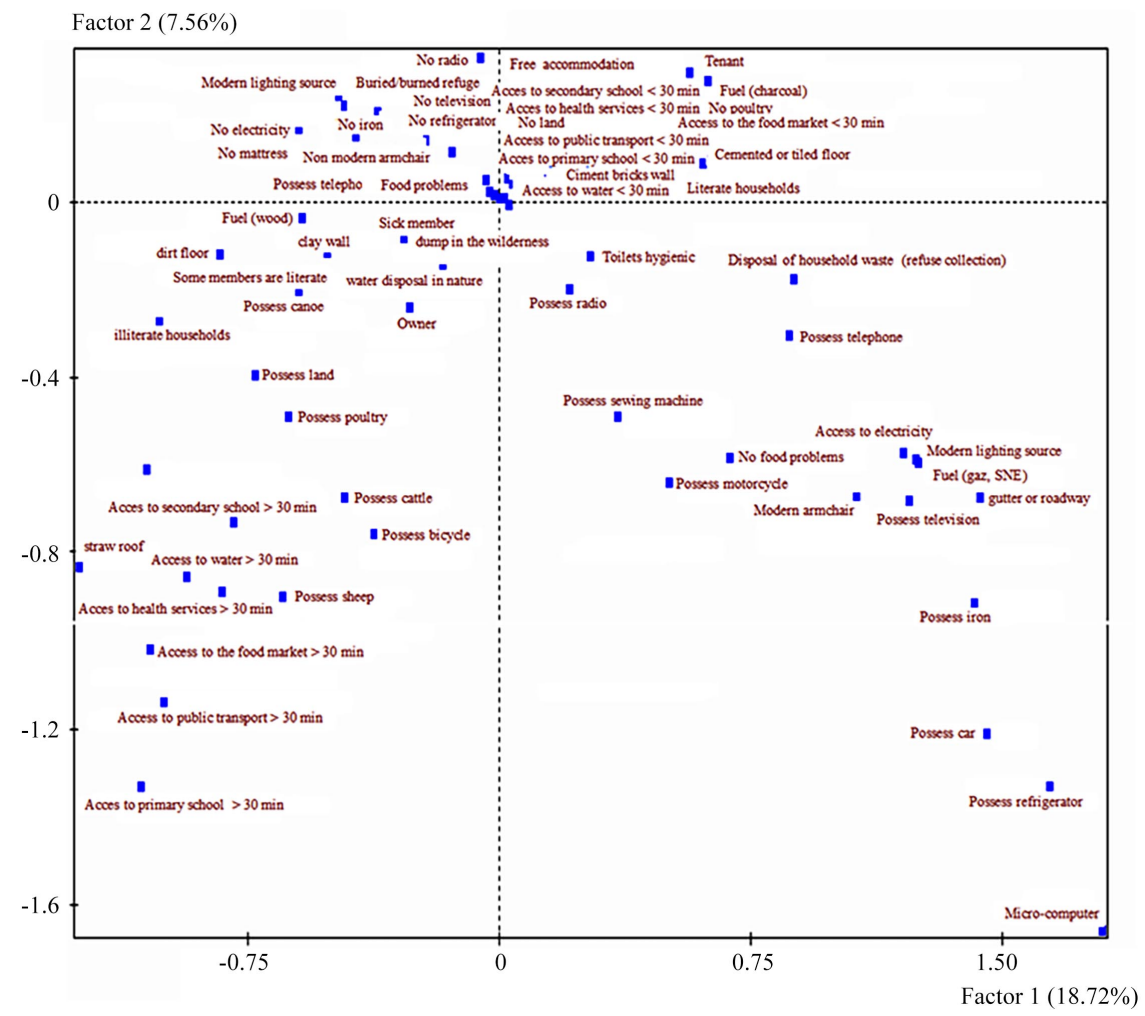

Figure 1. Principal plane of the preliminary MCA. 
The quadrant $(+,-)$, that is $F_{1}>0 ; F_{2}<0$ is the non-poor area. These wealthy households live in houses with sanitation toilets using an appropriate drainage system (sewerage and gutter systems) and a convenient system for the disposal of household waste, including public or NGO bins. They have access to modern lighting. As fuel for cooking, they use either gas or electricity. In addition, these non-poor households have access to means of communication: radio, telephone and television. Not surprisingly, these households are equipped with modern conveniences and amenities such as modern chairs, refrigerators, irons, sewing machines, microcomputers, motorcycles and cars. Finally, it would not surprise anyone if we found that these households do not have food problems.

\subsection{Final MCA on CIP Variables}

The objective of this second MCA is to select the relevant variables to be used in the construction of the composite indicator poverty according to the procedure mentioned above. In the end, this procedure allowed only 20 variables to be selected. These variables are presented in Table 2. Thus, a second MCA was carried out comprising 5002 individuals and 20 variables (with 42 modalities).

Table 2. Final list of 20 variables and 42 modalities for the CIP.

\begin{tabular}{|c|c|}
\hline Variables & Modalities \\
\hline \multicolumn{2}{|l|}{ Education } \\
\hline Literacy rate & $\begin{array}{l}\text { Illiterate households/Households in which } \\
\text { some members are literate/Households in } \\
\text { which all members are literate }\end{array}$ \\
\hline Access to a primary school in less than & Less than 30 minutes/More than \\
\hline 30 minutes & 30 minutes \\
\hline Access to a secondary school in less than & Less than 30 minutes/More than \\
\hline 30 minutes & 30 minutes \\
\hline \multicolumn{2}{|l|}{ Health } \\
\hline Access to health services in less than & Less than 30 minutes/More than \\
\hline 30 minutes & 30 minutes \\
\hline \multicolumn{2}{|l|}{ Drinking water } \\
\hline Source of drinking water & $\begin{array}{l}\text { Drinking water/Undrinkable } \\
\text { water }\end{array}$ \\
\hline Access to water in less than 30 minutes & $\begin{array}{l}\text { Less than } 30 \text { minutes/More than } \\
30 \text { minutes }\end{array}$ \\
\hline \multicolumn{2}{|l|}{ Housing } \\
\hline Nature of the roof & $\begin{array}{l}\text { Roof solid (sheet metal, tile, cement)/straw } \\
\text { roof and other }\end{array}$ \\
\hline Nature of walls & Cement bricks / clay wall \\
\hline
\end{tabular}


Continued

Nature of floor

Sanitation

Type of toilets

Energy

Type of lighting

Electricity in the household

Fuel

Communication

Television

Radio

Telephone

Access to public transport in less than

30 minutes

Goods of comfort, equipment, and other assets

Iron

Yes/No

Refrigerator

Yes/No

Modern armchair

Yes/No

floor source

Yes/No

Yes/No

Yes/No
Cemented or tiled floor/dirt

Toilets hygienic/Toilets unhygienic

Modern lighting source/non-modern lighting

Electricity/No electricity

Gaz, SNE, oil /Charcoal/Wood

Less than 30 minutes/More than

30 minutes

SNE: state-owned electricity company.

The reduction of the variables increased the explanatory power of the principal plane $F(1,2)$. In fact, the explanatory power of the first factor increased from $18.72 \%$ to $26.67 \%$ and that of the second factor from $7.56 \%$ to $11.03 \%$. The plane $F(1,2)$ now explains nearly $38 \%$ of the total inertia. In Figure 2 , the configuration of points is more sparse than in Figure 1, but still looks parabolic. And as before, the more one tends towards the right of the figure, the less one becomes poor.

This plane highlights three types of poverty: 1) infrastructure poverty characterized by poor access to basic infrastructure (health, education, food markets). This poverty is closely linked to the policy and capacity of the State to provide the country with the necessary basic infrastructure that can contribute to improving the living conditions of the population; 2) vulnerability of human existence. This poverty is linked to the characteristics of housing, sanitation and lighting. It is the most perceptible poverty. It mainly concerns illiterate households; 3) poverty of comfort. This is reflected in the under-equipment of households in terms of communication goods, equipment and comfort such as telephones, television, radio, iron, refrigerator and modern chairs. 


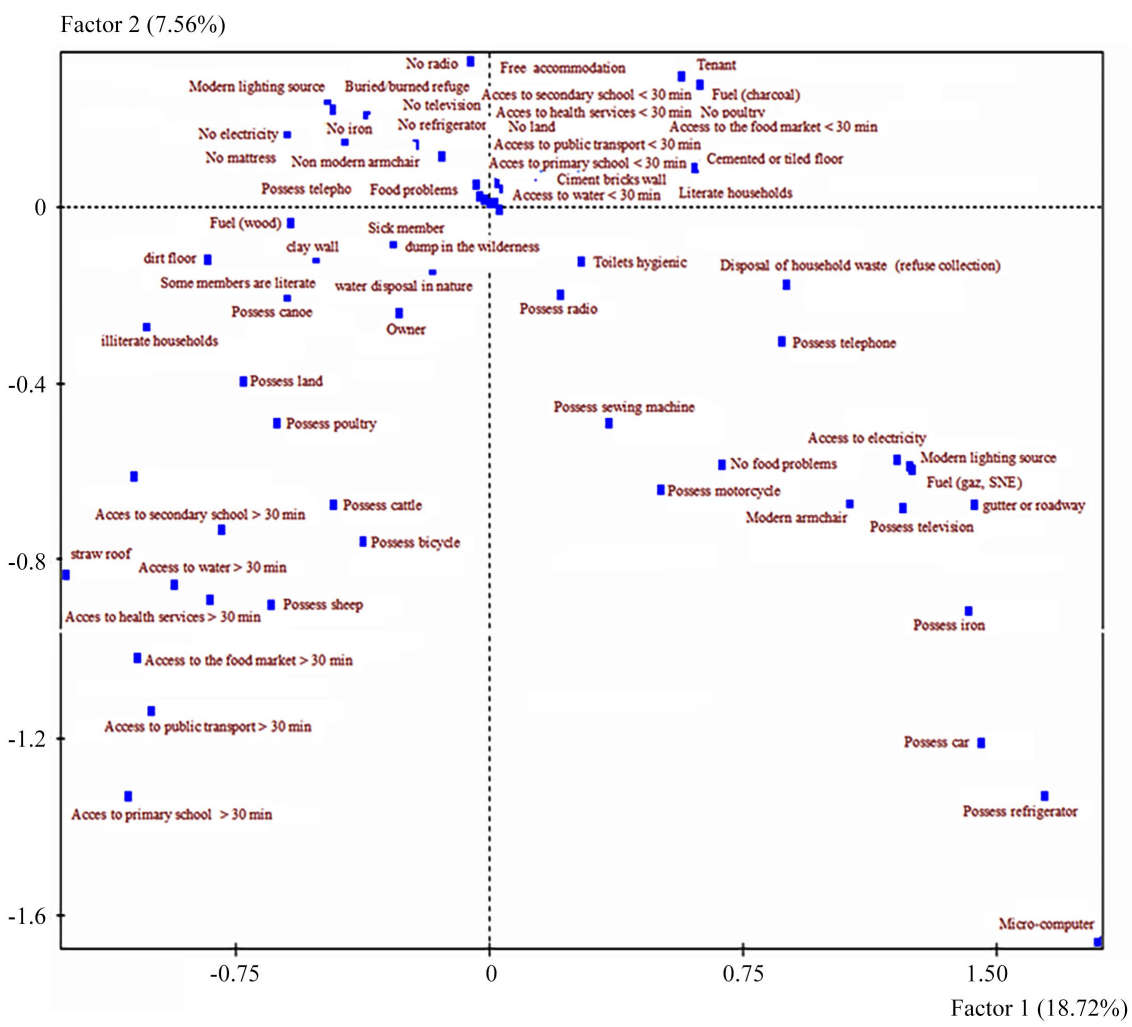

Figure 2. Principal Plane of the final MCA.

\subsection{Weights of the CIP}

Table 3 provides the scores of the different indicators used as weights for the composite poverty indicator. Recall that the weights correspond to the standardized scores on the first factor axis. Modalities with a positive score increase well-being, while those with a negative score decrease it. The modalities with the highest positive scores are those related to comfort. These include possession of a refrigerator, iron, television and use of modern lighting. Thus, access to these goods and services is limited to a certain number of affluent households. On the other hand, the modalities with the highest negative scores on the first axis concern the most accessible goods and services. In our case, it is the housing under a straw roof and the materials of the dirt floor, the lack of drinking water, the lack of access to the food market, primary school and transport and finally illiteracy. As can be seen, the weightings provided by MCA give the latter an interesting property: to separate at best, poor and rich. The logic of this method is therefore clear: the rarer the rarity of a modality, the greater its weight. Thus, MCA assigns important weights to rare or luxury goods in increasing well-being. This logic therefore aims at a better identification of poor populations. A household will be all the poorer if it does not have access to basic goods that are accessible to the majority of the population.

Table 3 also gives the contributions of the modalities to the construction of the first axis. 
Table 3. Scores, contributions and square cosines of the final MCA.

\begin{tabular}{|c|c|c|c|c|}
\hline Variables/Modalities & $\begin{array}{l}\text { Scores on the } \\
\text { first axis }\end{array}$ & $\begin{array}{l}\text { Cosines } \\
\text { squared }\end{array}$ & Contribution & $\begin{array}{l}\text { Distance to } \\
\text { the center }\end{array}$ \\
\hline \multicolumn{5}{|l|}{ Nature of the roof } \\
\hline Roof solid & 0.15 & 0.19 & 0.30 & 0.12 \\
\hline straw roof and other & -1.23 & 0.19 & 2.80 & 8.18 \\
\hline \multicolumn{5}{|l|}{ Nature of walls } \\
\hline Cement bricks & 0.23 & 0.12 & 0.60 & 0.44 \\
\hline Clay wall & -0.52 & 0.12 & 1.40 & 2.27 \\
\hline \multicolumn{5}{|l|}{ Nature of floor } \\
\hline Cemented/tiled floor & 0.57 & 0.47 & 3.30 & 0.69 \\
\hline dirt floor & -0.83 & 0.47 & 4.80 & 1.46 \\
\hline \multicolumn{5}{|l|}{ Type of toilets } \\
\hline Toilets hygienic & 0.8 & 0.09 & 0.70 & 0.85 \\
\hline Toilets unhygienic & -0.33 & 0.09 & 0.90 & 1.17 \\
\hline \multicolumn{5}{|l|}{ Electricity in the household } \\
\hline Electricity & 1.24 & 0.61 & 7.40 & 2.53 \\
\hline No electricity & -0.49 & 0.61 & 2.90 & 0.40 \\
\hline \multicolumn{5}{|l|}{ Type of lighting } \\
\hline Modern lighting source & 1.27 & 0.60 & 7.50 & 2.69 \\
\hline Non-modern lighting source & -0.47 & 0.60 & 1.30 & 0.37 \\
\hline \multicolumn{5}{|l|}{ Source of drinking water } \\
\hline Drinking water & 0.37 & 0.38 & 1.70 & 0.36 \\
\hline Undrinkable water & -1.03 & 0.38 & 4.80 & 2.81 \\
\hline \multicolumn{5}{|l|}{ Access to the food market } \\
\hline Less than 30 minutes & 0.26 & 0.27 & 0.90 & 0.25 \\
\hline More than 30 minutes & -1.03 & 0.27 & 3.70 & 3.96 \\
\hline \multicolumn{5}{|l|}{ Access to a primary school } \\
\hline Less than 30 minutes & 0.09 & 0.09 & 0.10 & 0.08 \\
\hline More than 30 minutes & -1.09 & 0.09 & 1.50 & 12.56 \\
\hline \multicolumn{5}{|l|}{ Access to a secondary school } \\
\hline Less than 30 minutes & 0.31 & 0.09 & 1.20 & 0.39 \\
\hline More than 30 minutes & -0.79 & 0.09 & 3.00 & 2.54 \\
\hline
\end{tabular}




\section{Continued}

Access to health services

Less than 30 minutes

More than 30 minutes

\section{Access to public transport}

Less than 30 minutes

More than 30 minutes

Iron

Iron

No iron

\section{Refrigerator}

Refrigerator

No refrigerator

Television

Possess television

No television

Radio

Radio

No radio

Telephone

Telephone

No telephone

Armchair

Modern armchair

No modern armchair

\section{Literacy rate}

Households illiterate

Some members are literate

Households literate

Fuel

Gaz, SNE

Charcoal

Wood
$-0.85$

0.09

$-1.00$

1.47

$-0.30$

$-0.14$

1.27

$-0.38$

0.24

$-0.31$

0.90

$-0.44$

1.11

$-0.23$

$-1.06$

0.08

1.30

14.07

$-0.49$

0.24

1.25

0.59

$-0.57$

0.19

0.10

0.09

0.19

1.40

11.51

0.09

6.20

4.92

0.09

1.30

0.20

0.44

3.90

11.79

0.44

0.30

0.08

$$
0.25
$$

6.30

3.39

0.25

1.90

0.30

0.77

0.48

0.50

1.30 
They describe the share of each modality in the total inertia of the axis. The most contributing modalities are those relating to modern energy and more specifically, access to electricity and lighting mode. Next come those relating to the possession of certain goods such as irons and televisions. The square cosines indicate the quality of representation of the modalities on axis 1 . The higher the square cosine, the more the modality is correlated with the axis. Here again, the best represented modalities are those related to modern energy, having the highest square cosines. Finally, the distance to the center is simply the square of the distance from the origin.

\subsection{Incidence of Multidimensional Poverty}

Households were classified according to the CIP. The results of this classification of households into two classes are given in Table 4.

Table 4. Proportion of classes.

\begin{tabular}{cccc}
\hline Classes & Minimum & Maximum & $\%$ \\
\hline Poor & -2.14 & 1.24 & 70.67 \\
Non poor & -0.69 & 2.26 & 29.33 \\
Total & -2.14 & 2.26 & 100 \\
\hline
\end{tabular}

As this table shows, the incidence of poverty with a hierarchical classification of households corresponds to the weight of the poor class, which is $70.67 \%$. This figure seems to be in line with results found in other African countries: $83.5 \%$ in Burkina Faso and $61 \%$ in Senegal [31]. Indeed, the fact is that studies on non-monetary poverty of basic needs show high rates of poverty exceeding often more than $2 / 3$ of households. From this CIP classification, the multidimensional poverty line can be determined as follows:

$$
M P L=\max C_{i}^{P} n_{i}^{P}+\min C_{i}^{R} n_{i}^{R}
$$

where $\max C_{i}^{P}$ and $\min C_{i}^{R}$ are respectively the CIP values in the poor and non-poor class: $n_{i}^{P}$ and $n_{i}^{R}$ the weights of the poor and non-poor class. From the maximum CIP value of 1.24 for the poor class and the minimum value of -0.69 for the non-poor class, the multidimensional poverty line can be calculated as the intermediate value separating the two classes. Applying the formula given above, 0.67 is found as the value of the CIP threshold. From this threshold, one could construct the different poverty measures such as the poverty headcount, poverty gap, and severity of poverty which are the most common indices used, all belonging to the family of Foster-Greer-Thorbecke (FGT) poverty measures [36]. So a multidimensional non-monetary poverty profile of basic needs can be produced.

\section{Conclusions}

The conceptual framework of poverty adopted in this work, offers another al- 
ternative for defining and studying poverty in Congo. Although it differs from the monetary approach, it usefully complements it, giving a broader meaning to the concept of poverty. It is in fact a contribution to the search for solutions to the various issues related to the problems of poverty and thus gives indications for a better perception of poverty.

This multidimensional approach to poverty is based on the calculation of a composite indicator constructed from a data analysis technique and takes several aspects into account. The indicator thus obtained makes it possible to classify households or groups of households and to draw up a multidimensional non-monetary poverty profile of basic needs.

The study revealed that Congolese households are not affected by the same type of poverty. Three types of non-monetary poverty were identified: poverty from the point of view of infrastructure, poverty reflecting the vulnerability of human existence, and poverty from the point of view of household comfort. Moreover, the incidence of poverty with a hierarchical classification of households corresponds to the weight of the poor class of about $70.67 \%$.

The method used, although very interesting, has some limitations: 1) it does not allow the contribution of each of the dimensions of poverty to overall poverty to be determined; in fact, the index can only be broken down into sub-groups but not into a single dimension (health, nutrition, education, housing, etc.) and it is therefore difficult to know the causes of poverty; 2) it is not possible to establish a hierarchy of the three types of non-monetary poverty detected and prioritize which to fight.

\section{Acknowledgements}

A first version of this text was circulated as a working paper at the National Institute of Statistics of Congo. We would like to thank colleagues at the Institute, notably Etaki Wa Dzon and Professor G. Kissita of the Université Marien Ngouabi in Brazzaville for their critical and fruitful contributions. Our thanks also go to F. Conan Kouassi, at the time a trainee at the Institute, for providing us the computer printouts of MCA and hierarchical classification interpreted in this paper. We are grateful to Editor and anonymous referee for their constructive feedback and comments.

\section{Conflicts of Interest}

The author declares no conflicts of interest regarding the publication of this paper.

\section{References}

[1] Alkire, S. (2011) Multidimensional Poverty and Its Discontents, In: Aglieta, M., et al., Eds., Measure for Measure, How Will Do We Measure Development? Proceeding of the 8th AFD-EUDN Conference 2010, Paris AFD, 55-90.

[2] Sen, A.K. (1976) Poverty, an Ordinal Approach to Measurement, Econometrica, 44, 219-231. https://doi.org/10.2307/1912718 
[3] CNSEE (2006) Enquête Congolaise auprès des Ménages pour l'évaluation de la pauvreté. Profil de pauvreté au Congo. Rapport d'analyse.

[4] Asselin, L.-M. and Dauphin, A. (1999) Poverty Measurement. A Conceptuel Framework. CECI. MIMAP. Training Session on Povery Measurement and Analysis, Laval University, Quebec.

[5] Marniesse, S. (1999) Note sur les différentes approches de la pauvreté. AFD, Département des politiques et études, Paris.

[6] Destremau, B and Salama, P. (2002) Mesures et démesures de la pauvreté. PUF, Paris. https://doi.org/10.3917/puf.sala.2002.01

[7] Sen, A.K. (1992) Inequality Re-Examined. Oxford University Press, Oxford.

[8] Sen, A.K. (1985) Commodities and Capabilities. North-Holland, Amsterdam.

[9] Deutsch, S. and Silber, J. (2005) Measuring Multidimensional Poverty: An Empirical Comparisons of Various Approaches. Review of Income and Wealth, 51, 145-174. https://doi.org/10.1111/j.1475-4991.2005.00148.x

[10] Bibi, S. (2005) Measuring Poverty in a Multidimensional Perspective: A Review of Litterature. CIRPEE, Université de Laval, Quebec.

https://doi.org/10.2139/ssrn.850487

[11] Maweki Batana, Y. (2008) Comparaisons multidimensionnelles de bien-être et de pauvreté: Méthodes, inférence et applications. $\mathrm{Ph}$. D, Université de Laval, Quebec.

[12] Alkire, S., Foster, J., Seth, S., Santos, M.E., Roche, J.S. and Ballon, P. (2015) Multidimensional Poverty Measurement and Analysis. Oxford University Press, Oxford. https://doi.org/10.1093/acprof:oso/9780199689491.001.0001

[13] Zadeh, L.A. (1965) Fuzzy Sets. Information and Control, 8, 338-353. https://doi.org/10.1016/S0019-9958(65)90241-X

[14] Dubois, D. and Prade, H. (1980) Fuzzy set and Systems, Theory and Applications, Academic Press, N.Y.

[15] Cerioli, A. and Zani, S. (1990) A Fuzzy Approach to the Measurement of Poverty. In Dagum, C. and Zenga, M., Eds., Income and Wealth Distribution, Inequality and Poverty Studies in Contemporary Economics, Springer, Berlin, 272-284. https://doi.org/10.1007/978-3-642-84250-4_18

[16] Cheli, B. and Lemmi, A. (1994) A Total Fuzzy and Relative Approach to the Multidimensional Analysis of Poverty. Economic Note by Monte dei Pashi di Siena, 24, 115-134.

[17] Ambapour, S. and Bidounga, R. (2012) Mesures de la pauvreté au Congo utilisant la logique floue. Journal Africa Statistika, 7, 412-424. https://doi.org/10.4314/afst.v7i1.3

[18] Maassoumi, E. (1986) The Measurement and Decomposition of Multidimensional Inequality. Econometrica, 54, 991-997. https://doi.org/10.2307/1912849

[19] Miceli, D. (1997) Mesure de la pauvreté. Théorie et application à la Suisse. Thèse de doctorat ès sciences économiques et sociale, Université de Genève, Genève.

[20] Maassoumi, E. and Lugo, M.A. (2008) The Information Basis of Multivariate Poverty Assessments. In: Kakwani, N. and Silber, J., Eds., Quantitative Approaches to Multidimensional Poverty Measurement, Palgrave Macmillan, London, 1-29. https://doi.org/10.1057/9780230582354_1

[21] Coelli, T., Prasada Rao, D.S. and Battese, G.E. (1998) In Introduction to Efficiency and Productivity Analysis. Kluwer Academic Publisher, Boston.

https://doi.org/10.1007/978-1-4615-5493-6 
[22] Lowell, C.A.K., Richardson, S., Travers, P. and Wood, L. (1994) Resources and Functionings: A New View of Inequality in Australia. In: Eichhorn, W., Ed., Models and Measurement of Welfare and Inequality, Springer Verlag, Heidelberg, 787-807. https://doi.org/10.1007/978-3-642-79037-9_41

[23] Ramos, X. (2008) Using Efficiency Analysis to Measure Individual Well-Being with an Illustration for Catalonia. In: Kakwani, N. and Silber, J., Eds., Quantitative Approaches to Multidimensional Poverty Measurement, Palgrave Macmillan, London, 155-177. https://doi.org/10.1057/9780230582354_9

[24] Ramos, X. and Silber, J. (2005) On the Application of Efficiency Analysis to the Study of the Dimensions of Human Development. Review of Income and Wealth, 51, 285-309. https://doi.org/10.1111/j.1475-4991.2005.00155.x

[25] Anderson, G., Crawford, I. and Leicester, A. (2008) Efficiency Analysis and the Lower Convex Hull Approach. In: Kakwani, N. and Silber, J., Eds., Quantitative Approaches to Multidimensional Poverty Measurement, Palgrave Macmillan, London, 176-191. https://doi.org/10.1057/9780230582354_10

[26] Lebart, L., Morineau, A. and Warwick, K.M. (1984) Multivariate Descriptive Statistical Analysis. John Wiley \& Sons, New York.

[27] Greenacre, M. and Blasius, J. (2006) Multiple Correspondence Analysis and Related Methods. Chapman \& Hall/CRC, New York. https://doi.org/10.1201/9781420011319

[28] Benzécri, J.-P. (1993) Correspondence Analysis Handbook. Marcel Dekker. CRC Press, New York. https://doi.org/10.1201/9780585363035

[29] Anderson, T.W. (1958) An Introduction to Multivariate Statistical Analysis. Wiley, New York.

[30] Klasen, S. (2000) Measuring Poverty and Deprivation in South Africa. Review of Income and Wealth, 46, 33-58. https://doi.org/10.1111/j.1475-4991.2000.tb00390.x

[31] Asselin, L.-M. (2009) Analysis Multidimensional Poverty and Cases Studies. Springer, New York. https://doi.org/10.1007/978-1-4419-0843-8

[32] Luzzi, G.F., Flückiger, Y. and Weber, S. (2008) A Cluster Analysis of Multidimensional Poverty in Switzerland. In: Kakwani, N. and Silber, J., Eds., Quantitative Approaches to Multidimensional Poverty Measurement, Palgrave Macmillan, London, 63-79. https://doi.org/10.1057/9780230582354_4

[33] Krishnakumar, J (2008) Multidimensional Measures of Poverty and Well-being Based on Latent Variables Models. In: Kakwani, N. and Silber, J., Eds., Quantitative Approaches to Multidimensional Poverty Measurement, Palgrave Macmillan, Macmillan, 118-134. https://doi.org/10.1057/9780230582354_7

[34] Naga, R.A and Bolzani, E (2008) Income, Consumption and Permanent Income, a MIMIC Approach to Multidimensional Poverty Measurement. In Kakwani, N. and Silber, J., Eds., Quantitative Approaches to Multidimensional Poverty Measurement, Palgrave Macmillan, Macmillan, 104-117.

https://doi.org/10.1057/9780230582354_6

[35] Asselin, L.-M. (2002) Composite Indicator of Multidimensional Poverty. CECI, Quebec, Canada.

[36] Foster, J.E., Greer, J. and Thorbecke, E. (1984) A Class of Decomposable Poverty Measures. Econometrica, 52, 761-766. https://doi.org/10.2307/1913475 